\title{
PSEUDOELASTIC BEHAVIOUR AND TWO WAY MEMORY EFFECT IN Cu-Zn-Al ALLOYS
}

\author{
C. ROGUEDA, P. VACHER, C. LEXCELLENT, L. CONTARDO* and G. GUÉNIN* \\ Laboratoire de Mécanique Appliquée, Faculté des Sciences, Université de Franche-Comté, La Bouloie, \\ Route de Gray, F-25030 Besançon cedex, France \\ *Groupe d'Etude de Métallurgie et de Physique des Matériaux, UA. 341, INSA, Av. A. Einstein, \\ F-69621 Villeurbanne cedex, France
}

\begin{abstract}
Different types of training sequences and two memory effect (TWME) of polycristalline $\mathrm{Cu}-\mathrm{Zn}-\mathrm{Al}$ alloys have been studied : Thin plates have been loaded in torsion and tests samples were loaded in pure tension.

Simultaneous resistance measurements were made to know the volume fraction of the martensite. As Friend, it is shown that the first martensite platelets formed are the most operational for training. In addition, the relation between the pseudoelastic strain $\varepsilon^{p e}$ and the martensite fraction $z$ is non linear.

The training can be quantified with the introduction of an internal kinematical stress $\underline{x}_{\mathrm{e}}$
\end{abstract}

\section{INTRODUCTION :}

In order to imagine some technological applications, the training process of shape memory alloys must be very well established. It is sought to verify the currently accepted assumption which consists in saying that an applied stress gradiant different from zero optimizes the training efficiency. Simultaneous resistivity measurements allow the volume fraction of the martensite evolution to be determined.

Training and two way memory effect (TWME) of polycristalline $\mathrm{Cu} \mathrm{Zn} \mathrm{Al}$ alloys has been studied for:

(i) Test samples in pure tension (with resistance measurements)

(ii) Thin plates loaded in torsion (with resistance measurements)

The training can be quantified with the introduction of an internal kinematical variable $\mathrm{X}_{\text {. }}$.

I - TRAINING USING THE SUPERELASTIC EFFECT AT A CONSTANT TEMPERATURE T :

\section{I.1 - Determination of the internal training variable $\mathrm{x}_{e}$ :}

Some cyclic loading-unloading tensile tests are presented in Fig. 1 ( $\mathrm{T}-\mathrm{M}_{\mathrm{s}}=$ $\left.23^{\circ} \mathrm{G}\right)$ and $F i g .2\left(\mathrm{~T}-\mathrm{M}_{\mathrm{s}}=28^{\circ} \mathrm{C}\right)$. The martensitic transformation threshold stress decreases with an increasing number of cycles $\mathrm{N}_{c}$. After the $15^{\text {th }}$ cycle, the stress-strain curve seems to become stable. The small ${ }^{c}$ residual plastic strain $\varepsilon^{p}$ determined after each cycle of transformation in the austenitic phase corresponds to point, line or volumic defects introduced during the phase transition [1]. $\varepsilon^{p}$ can be used as an indicator for the training process [2]. 


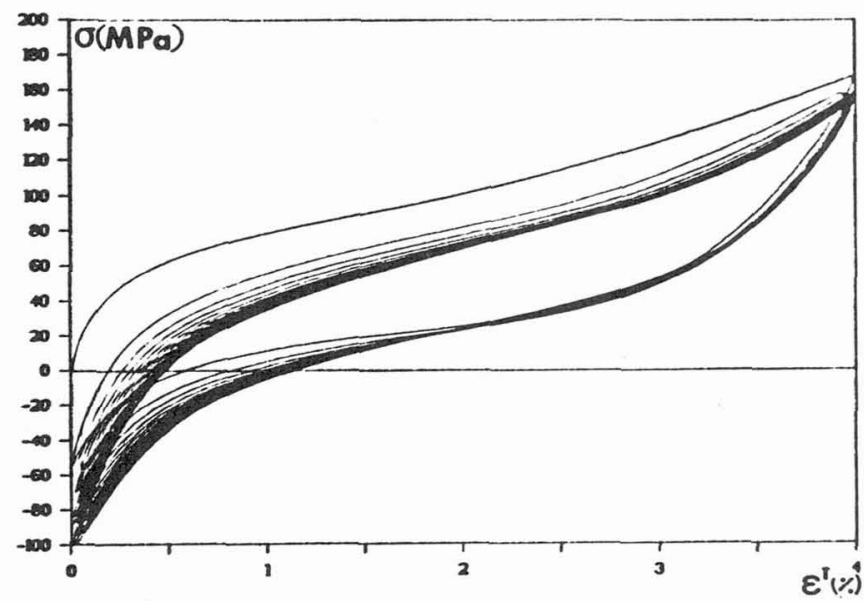

Fig. 1 : Stress-strain curve of a loadingunloading tensile test $\left(T-M_{s}-23^{\circ} \mathrm{C}\right)$.

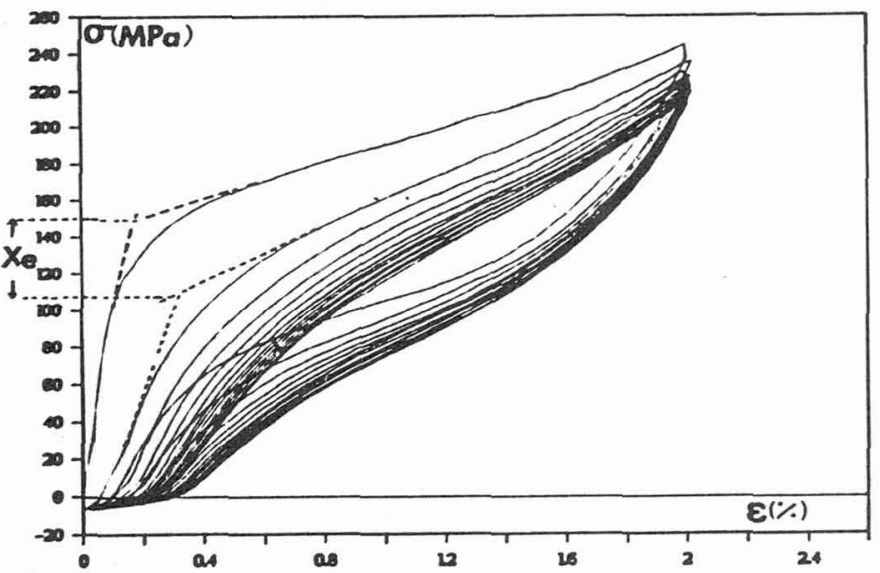

Fig. 2 : Stress-strain curve of a loadingunloading tensile test $\left(T-M_{s}=28^{\circ} \mathrm{C}\right)$

The kinematical training variable $x_{\text {e }}$ is introduced as a measure of the diminution in the transformation threshold during the training sequences [3]. During the first unidirectional loading, the loading function is defined by :

$$
f=\sigma_{0}(0)-b\left(T-M_{s}\right)=0
$$

with $\mathrm{b}=2 \mathrm{MPa} /{ }^{\circ} \mathrm{C}$ for this alloy.

During the $(\mathrm{N}+1)^{\text {th }}$ cycle, this expression becomes :

$$
\sigma_{0}(N)+\mathrm{X}_{e}(\mathrm{~N})-\mathrm{b}(\mathrm{T}-\mathrm{Ms})=0
$$

This internal stress is representative of the structure of the material which is polarized by the dislocations created during the training. The evolution of $x_{e}$ can be described by :

$$
x_{e}=x_{e 0} \text { th }\left(N_{c} / C t e\right)
$$

$\mathrm{X}_{\mathrm{e} 0}$ corresponds to the limit value of $\mathrm{x}_{\mathrm{e}}$ (Fig.3). 


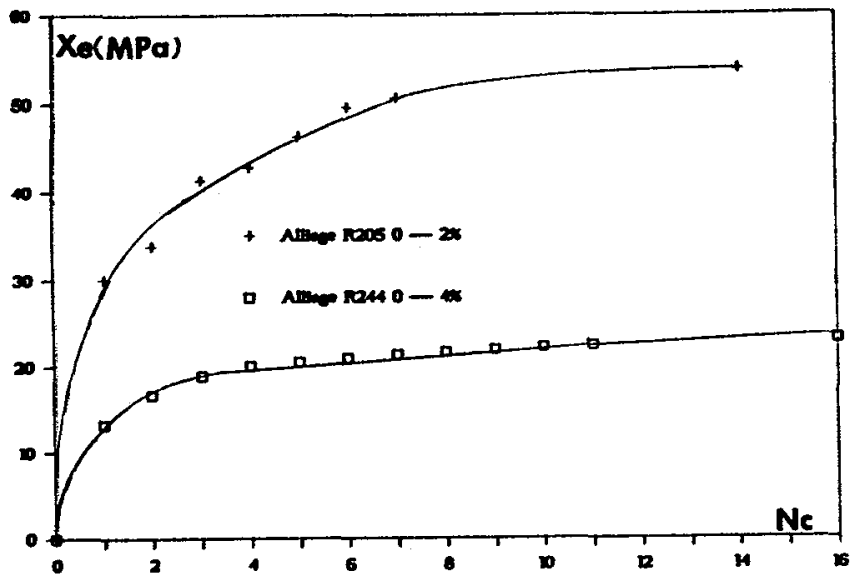

Fig. 3 : Evolution of the Kinematical training variable (Fig.1 and Fig.2 cases)

I.2 - Pseudoelastic behaviour 1aw :

Total strain can be divided into two components : a classical elastic strain $\varepsilon^{e}$, equal to $\sigma / \mathrm{E}$ ( $\sigma$ is the applied stress and $\mathrm{E}$ the Young modulus), and a transformation strain $\varepsilon^{\text {pe }}$. It can be shown that $\varepsilon^{\text {pe }}$ and $z$ are proportional :

with $\gamma\left(T-M_{s}=23^{\circ} \mathrm{C}\right)=0.05$

$\gamma$ is the maximum pseudoelastic strain possible when the transformation is finished.

With an increasing number of cycles, this proportionality is less and less obvious, as can be seen in Fig.4.

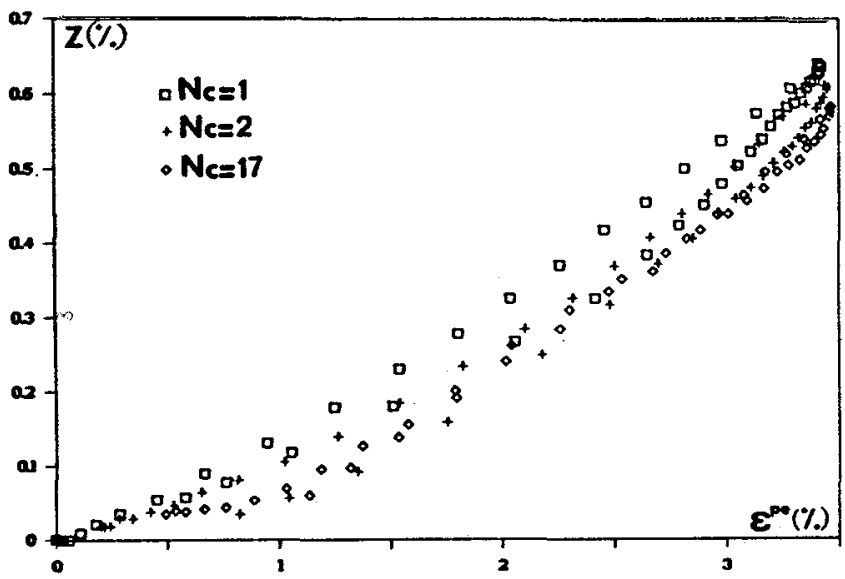

FIG.4 : Proportionality between $\varepsilon^{\mathrm{pe}}$ and $z$ is established at every cycle? 


\section{3 The training efficiency :}

The training efficiency is defined by :

$$
r=\frac{\left(\varepsilon^{p e}\right)_{0=0}}{\left(\varepsilon^{p e}(N)\right)_{0 \neq 0}}
$$

$\left(\varepsilon^{p e}\right)_{0=0}$ is the pseudoelastic strain obtained in the martensitic phase when the alloy is trained.

$\left(\varepsilon^{\mathrm{pe}}(\mathrm{N})\right)_{0=0}$ is the pseudoelastic strain measured in the martensitic phase during the last cycle.

This efficiency is about 37 percent, which is a relatively small value.

\section{II - TRAINING BY A CONSTANT TENSILE STRESS WITH A VARIABLE TEMPERATURE :}

Uniaxial tensile stress $(\sigma=40 \mathrm{MPa})$ is applied at $\mathrm{T}) \mathrm{M}_{\mathrm{s}}^{\circ}$. The sample alloy is unrefined one and $\mathrm{M}_{\mathrm{s}}^{0}$ is equal to $15^{\circ} \mathrm{C}$. The total strain evolution with respect to the temperature during the thermal sequence $\left(0^{\circ} \mathrm{C} \leftrightarrow 40^{\circ} \mathrm{C}\right)$ is presented $F i g .5$. The variation of the transformation threshold $M_{s}^{\sigma}$ during the training sequence gives a new definition of the training variable $\mathrm{X}_{e}^{s}$ :

$$
X_{e}(N)=b\left(M_{s}^{\sigma}(N)-M_{s}^{0}\right)-\sigma
$$

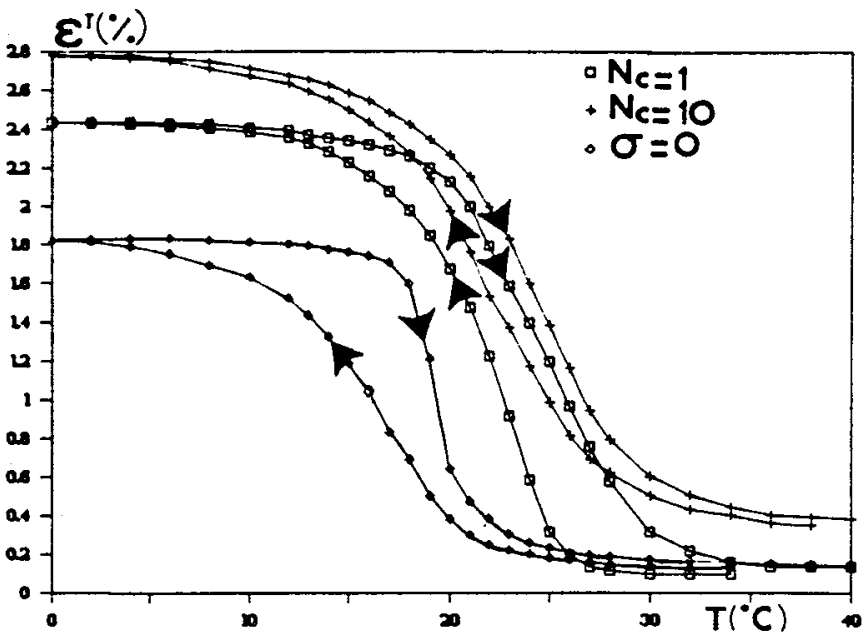

Fig.5 : Strain-temperature curve of a loading tensile test $(\sigma=40 \mathrm{MPa})$

Moreover, the $A_{f}^{0}$ temperature seems to stay constant during training. This is also a classical result [4].

The training efficiency is equal to 67 percent, which is a quite good value. This result put into question the current idea stating that the presence of a stress gradient is essential to obtain effective training.

The sample is then maintained at a constant temperature $\left(\mathrm{T}-\mathrm{M}_{\mathrm{s}}=8^{\circ} \mathrm{C}\right)$ in the austenitic phase and without any stress during four months. As a result, the training efficiency decreases to 58 percent. Simultaneous resistivity measurements during the training show that $\varepsilon^{p e}$ and $z$ are still proportional (Fig. 6). 


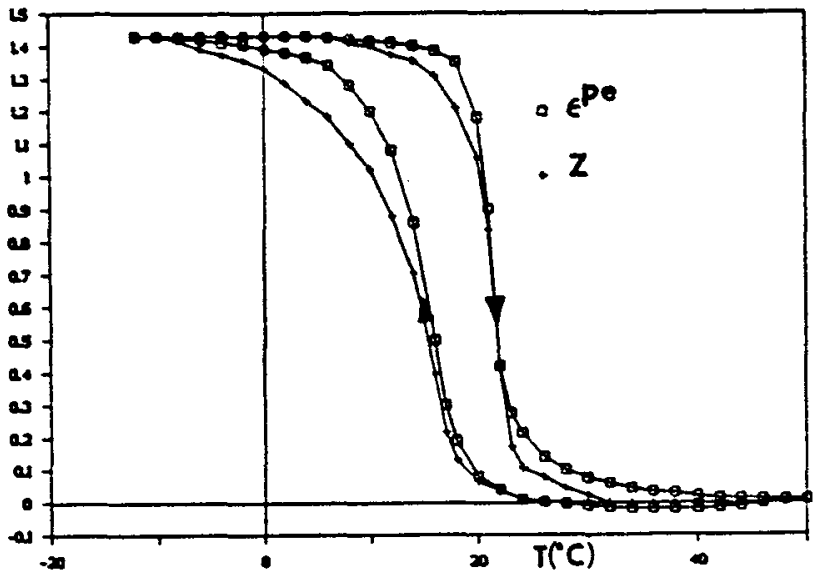

Fig. 6 : $\varepsilon^{\text {pe }}$ and $z$ are still proportional after a maintaining of 4 months without any stress

\section{III - TRAINING BY CONSTANT STRESS GRADIANT AND VARIABLE TENPERATURE :}

Electric resistivity measurements realized "in situ" on thin plates loaded in torsion [4] indicate that $\varepsilon^{p e}$ and $z$ are non longer proportional. Actually, it can be observed in Fig.7 that during the first cycle, the first 25 percent of martensite carries about 48 percent of transformation strain. In the same way, during the inverse transformation, 25 percent of martensite allows the sample to retain 75 percent of its maximum strain. These results confirm those that Friend [5] obtains on coil-springs. The first martensitic platelets to appear are more efficient than those that following and seem to be the last to vanish. This situation does not significantly change during the training.

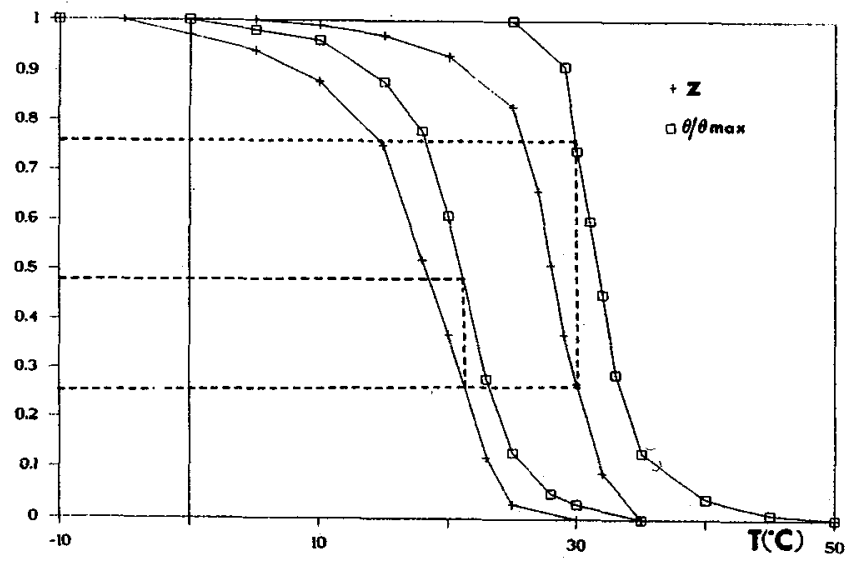

Fig. 7 : Thin plates loading in torsion : simultaneous evolution of $\varepsilon^{\text {pe }}$ and $z$ during the thermal sequence (first cycle) 


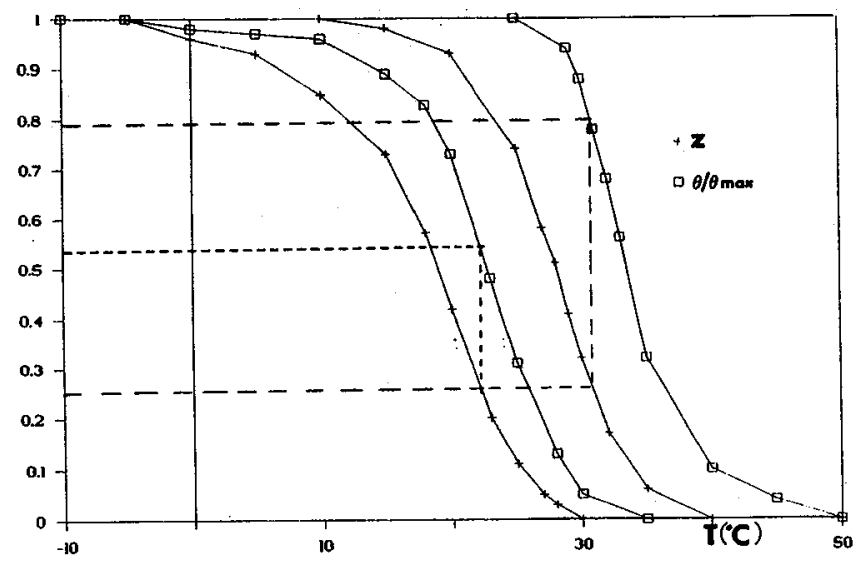

Eig. 8 : Thin plates in torsion : simultaneous evolution of $\varepsilon^{\text {pe }}$ and $z$ during the thermal sequence (seventh cycle)

At the seventh cycle (Fig.8), the first 25 percent of the martensite produces 55 percent of the maximum pseudoelastic strain; during the reversion, 25 percent of martensite correspond to 78 per cent of the remaining strain. This result indicates that the platelets which were created first become more and more efficient during the training process.

This sort of training gives a good efficiency, equal to 64 percent, which is as high as that given by traction.

In this case, where the stress gradient which is different from zero, the behaviour law can be generalized as follows :

$$
d \underline{\varepsilon^{p e}}=K \Phi^{\prime}(z) \underline{\operatorname{dev}\left(\sigma+X_{e}\right.} 2 d z
$$

where

$$
\Phi(z)=z(2-z)
$$

$X_{e}$ is determined by equation (6).

\section{CONCLUSION :}

During the training processes where a homogeneous and constant stress is applied, $\varepsilon^{p e}$ and $z$ seem to be proportional in every point of the sample. Thin plates loaded in torsion are structures where the stress gradiant is different from zero. The first martensitic variants to appear are located in this structure and are more efficient for yielling good training results. The nonproportionality between macroscopic variables, such as the torsion angle or the coil-springs elongation, and the volume proportion of martensite is therefore quite natural.

\section{REFERENCES :}

[1] J. PERKINS, P. BOBOWIEC, Met. Trans 17 A (1986), 195

[2] E. PATOOR, A. EBERHADT, M. BERVEILLER, to appeared in Acta. Met.

[3] Y. BERVEILLER, PATOOR, Rev. Trait. Th. (1990), 234

[4] L. CONTARDo, Thèse INSA de Lyon (1986)

[5] C.M. FRIEND, Sripta Met. 20, (1986), 995 